\title{
COMPARATIVE EVALUATION OF MANDIBULAR OVERDENTURE WITH SINGLE CANINE SPLINTED OR UNSPLINTED TO IMPLANT ON THE ABUTMENT SUPPORTING STRUCTURES
}

\author{
Sahar KH. Abdel-Bary*
}

\begin{abstract}
Purpose: The purpose of this clinical study was to evaluate and compare the effect of mandibular overdenture with single canine splinted or unsplinted to implant on the abutment supporting structures.

Methods: Ten male patients, were included in this study from the outpatient clinic, Faculty of Dentistry, Misr University for Science and Technology, having only single standing mandibular canine opposing completely edentulous maxilla were selected. The selected patients were divided randomly by closed envelope into two equal groups according to their overdenture supporting system: Group I: Patients received mandibular overdenture supported by natural canine and implant at the contra-lateral canine area. Group II: Patients received mandibular overdenture supported by natural canine connected by bar attachment to the implant at the contra-lateral canine area. The abutments were evaluated clinically and radiographically (marginal bone height and density changes). These evaluations were established at time of insertion, 6, 12 months. The data were collected and tabulated.
\end{abstract}

Results: The implants in Both group showed successful clinical osseointegration till the end of the follow- up period. There was statistically significant difference at $\mathrm{p} \leq 0.05$ between the two studied groups in the decrease of marginal bone height through all intervals of follow-up period where group I showed less marginal bone resorption than group II; also, there was statistically significant difference at $\mathrm{p} \leq 0.05$ between the two studied groups on bone density during (0-12 months) interval, while there was no statistically significant difference through (0-6 months and 6-12 months) of follow-up period. Group I showed more increase in bone density than group II

Conclusion: Within the limitations of this study, overdentures supported by the natural canine and an implant at the contralateral side of the arch had the best effect on the supporting structures of the abutments compared to the group of individuals with implant splinted by bar .

KEYWORDS: Single dental implant, tooth abutment, precision attachment, overdenture.

* Ass. Prof. of Prosthodntic Department, Faculty of Dentistry, Misr University for Science and Technology. 


\section{INTRODUCTION}

Alveolar ridge resorption after tooth extraction discourage the stability and the retention of complete dentures ${ }^{(1)}$. So that, preservation of the canines particularly in the mandibular arch, offers great advantages, anchoring an overlay denture to retained roots enhances denture stability and provides numerous functional advantages ${ }^{(2)}$

The use of a single canine as overdenture abutment is considered a risky procedure. The overdenture will be rotates around many rotational axes. Also, different supporting mechanisms on both sides of the arch which encourage the patient to use only the tooth side during mastication. Finally, both support and stability will be deteriorated and make the denture more prone to fracture ${ }^{(3)}$.

Osseointegrated dental implants supporting overdenture is being dictated by the prosthodontic design and so it was logical to develop a prosthetic design that minimized stress concentration, alignment problems, and esthetic restrictions, and avoid anatomic complications. ${ }^{(4,5)}$.

Implant-supported overdentures provide a good opportunity to improve the quality of life and oral health. There are many advantages of implantsupported overdentures in comparison with the conventional dentures, including good retention and stability, reduced resorption of the residual ridge, improved esthetics, and function. ${ }^{(6)}$

Particularly in the mandible, reduction of the crown height after endodontic treatment permits improved support for the removable prosthesis.(2) This combined tooth-implant supported overdenture can improve the masticatory efficiency in a cost-effective manner and offer evenly force distribution. ${ }^{(7)}$

A major limiting factor for widespread acceptance of implant supported overdentures continues to be the high costs and the invasive nature of implant surgeries. ${ }^{(6,7)}$ Single implant retained overdentures have gained popularity in recent years due to their lowered costs and minimal tissue trauma. ${ }^{(8-10)}$
According to Alsabeeha et al., restoring single implant retained mandibular overdentures using different ball attachment systems which help to achieve satisfactory clinical outcomes. ${ }^{(11,12)}$ However, one of a ball-cap design disadvantages includes loss of tension of the spring mechanism and wear of the ball attachment that limits its widespread application, which adds significant costs during the maintenance phase of the overdenture. The ball attachment recorded the lowest strain around abutments in comparison to other attachments. ${ }^{(13)}$

Carpentieri (14) explained that bar attachment provides a direct mechanical attachment between the overdenture and the supporting fixtures, so fixtures can be connected for mutual support. It acts as a splint between abutments and can also provide either rotational movement between the bar and the overlying sleeve (bar joint) or rigid fixation (bar unit).

Cohen \& Orenstein ${ }^{(15)}$ found that when implants and natural tooth are combined, forces on the abutments need to be controlled so that neither the teeth nor the implants sustain excessive amounts of force. Anon-rigid attachment that used in the implant crown acts to limit the cantilever forces exerted on the natural tooth. Therefore, any difference in the movement between the tooth and the implant will be compensated through its stress breaking effect.

El-Charkawi et al., ${ }^{(16)}$ studied the use of a resilient layer material under the superstructure of the implant in a connected tooth-implant supported prosthesis model. Their FEA proposed that this new modification could mimic the structural natural tooth unit by allowing movement of the superstructure without movement of the implant when the model was loaded. Furthermore, the use of resilient resin filler between two layers of hard denture resin bases could also act to reduce forces transmitted to the alveolar ridge ${ }^{(17)}$.

Implant-supported overdenture is a reliable treatment option for the patients with edentulous mandible when they have difficulty in using 
complete dentures $^{(18)}$. Several options have been used for implant-supported overdenture attachments. Among these, bar attachment system has greater retention and better maintainability than others.

Thus, this clinical study was conducted to evaluate and compare the effect of mandibular overdenture with single canine splinted or unsplinted to implant on the abutment supporting structures.

\section{MATERIALS AND METHODS}

Ten male patients, with age ranging from 4864 years, participated in this study were selected from the outpatient clinic, Faculty of Dentistry, Misr University for Science and Technology, having only single standing mandibular canine in a good periodontal condition opposing completely edentulous maxilla, with no systemic or oral diseases that may affect the alveolar bone condition. Heavy smokers, ${ }^{(19)}$ uncontrolled diabetics, as well as patients that may previously received radiotherapy, or chemotherapy should be excluded. Periapical radiographs were made for the proposal abutment tooth to evaluate the crown-root ratio, the apical condition of the abutment and their alveolar bone support. All patients were thoroughly informed about the study and each signed a written informed consent form.

Abutment was reduced in the form of domeshaped 2-3 $\mathrm{mm}$ in length above the free gingival margin with approximately $30^{\circ}$ labial wall inclination and $15^{\circ}$ lingual and proximal_walls inclination. All line angles were rounded and smoothed followed by topical application of fluoride (Fig.1). All the selected patients were rehabilitated with maxillary complete dentures opposing mandibular overdentures were constructed from heat-cured acrylic resin following the conventional technique. The overdenture was duplicated using alginate impression material in a duplicated flask. A gutta percha ball ( $0.5 \mathrm{~mm}$ diameter) was fixed by sticky wax at the canine area of the lower residual alveolar ridge inside the duplicate mold. Then clear auto-polymerized acrylic resin template was constructed. Panoramic x-ray films were taken to evaluate the bone height and determine the position of the mental foramen and shape of the bone in the anterior area of the mandible.

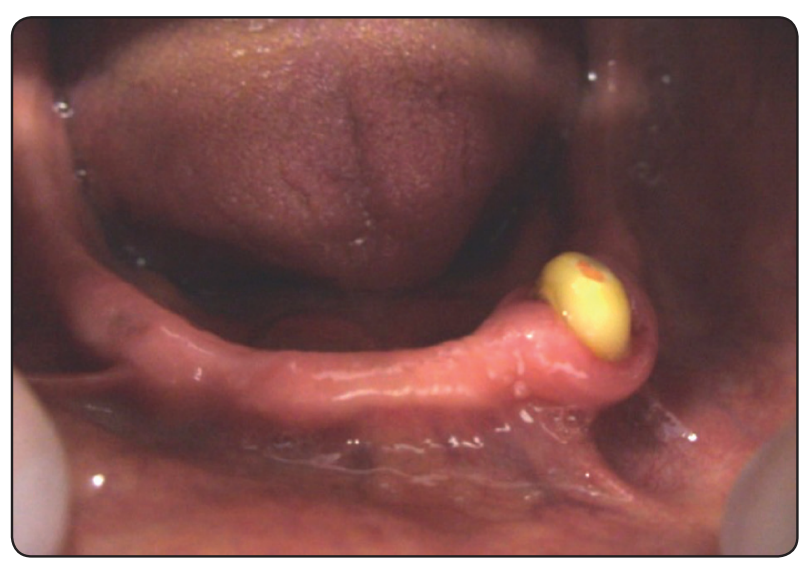

Fig. (1) Abutment tooth after preparation

Patients contribute in these study were received Legacy II Implant System with internal hex platform (Implant Direct LLC, USA-Canada). Implants were titanium alloy, tapered, screwed, threaded with Soluble Blast Media (SBM) textured surface treatment and were $3.7 \mathrm{~mm}$ in diameter and $13 \mathrm{~mm}$ in length. Implant were inserted in the contralateral canine region by aid of surgical stent. A nonsubmerged technique was followed and healing collars were mounted onto the implants. Seven days following the surgery, removable denture wearing was avoided as much as possible, patients were recalled, sutures were removed, and healing collars were un-screwed, and permanent implant abutment was assembled over the fixture. The implant abutment was removed and then prepared for coping configuration followed by finishing and polishing.

The implant abutment was reassembled again over the fixture and screwed using fixation screw (Fig.2). New dentures base were constructed over abutments with positive contacts at the top of the two abutments and minimal relief around their lateral walls and free gingival margins. During denture 
insertion, dentures were painted with pressure indicating paste to clarify the area required relief. Relief was done around the free gingival margin and lateral walls of the abutment leaving the top of the abutment in direct contact with the fitting surface of the overdenture.

Implants were tested for success of osseointegration as indicated by the absence of mobility, pain, peri-implant radiolucency in x-ray and metallic sound on percussion.

The patients were instructed to follow post surgical medication. After complete healing, the selected patients were divided randomly by closed envelope into two equal groups according to their design.Group I: : Patients having single standing canine covered by dome-shaped cast coping-post assembly and implant at the contra-lateral canine area.Group II: Patients having single standing canine covered by dome-shaped cast coping-post assembly splinted to implant at the contra-lateral canine area with a custom made bar attachment. Fine horizontal groove to receive grip from the medium retentive plastic bar clip.

The bar was fixed passively using fixation screw to the bar abutment on both sides. The tooth-bar

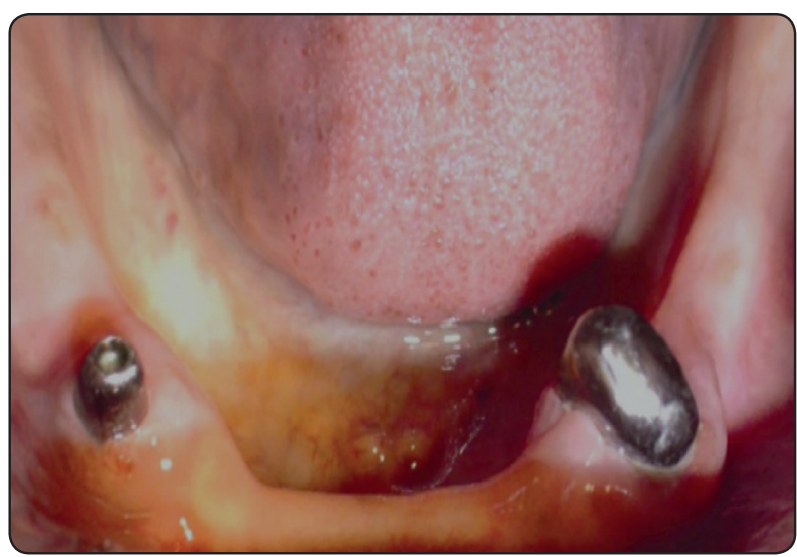

Fig. (2) Cemented coping and abutment fixed to the implant (group I) abutment was cemented (by adhesive resin cement) to metal coping covering the natural tooth while implant-bar abutment was fixed by screwing to the fixture using the long fixation screw. Fig.(3).

After insertion of the bar in the patient mouth, new overdenture was constructed following the conventional technique after obliterating all undercuts below the bar. At the time of denture insertion direct pick-up of the bar clip by self-cured acrylic resin was done in the patient's mouth. The bar clip was checked then adapted at the middle of the bar. The fitting surface of the overdenture at the bar area was relieved carefully. Small hole was performed over the area covering the clip. The denture was checked in the patient mouth for passive seating.

The finished dentures were delivered to the patient after performing the needed occlusal adjustment. Patients were encourage to oral and denture hygiene measures and recalled for adjust their dentures, and for collecting the data at time of insertion, 6 months, and 12 months. Bone height and density were measured around the natural abutment tooth.

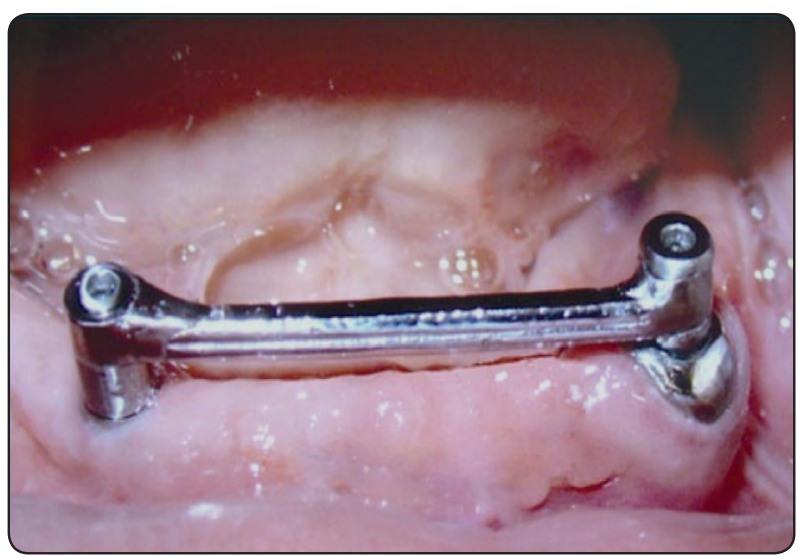

Fig. (3) The cast bar fixed in place (group II). 


\section{Evaluation of marginal bone height}

By using long cone parallel technique, serial periapical radiograph of the natural abutment was performed. A radiographic acrylic template was fabricated by duplicating the overdenture of the patient and having the imprints of the Rinn XCP bite plate. Radiographs were taken using Trophy X-ray machine, and films were processed by an automatic processor for standardization. Radiographs were taken for abutments at scheduled follow-up visits; at time of denture insertion , 6 months and 12 months after denture insertion.

All radiographic films were scanned using digital scanner and processed to the Digora ${ }^{\circledR}$ software (version 1.51 for windows). After importing the images on the program, patient cards were filled for each patient then the images were labeled. The stored images were projected onto a monitor. ${ }^{(21)}$. The average of the values measured for the times of the follow-up period was calculated and considered the relative change of bone height of this period. (from denture insertion till 6 months ( 0-6 m) and from 6 till 12 months (6-12 m)).

\section{Evaluation of the bone density}

The software of the Digora system was used for evaluation of the change in the bone density mesially and distally to the abutments. This was done by making a line on the mesial and distal surfaces of the abutment. The line extended from the crest of the alveolar ridge to the apex of the tooth and passed adjacent to the space of the lamina dura parallel to the surface of the root. The value indicating bone density along each line was recorded and the mean value of all abutments reading was calculated.

All data of radiographic and clinical evaluations were collected and tabulated then statistically analyzed.

\section{Statistical analysis}

The statistical analysis of data was performed using Excel program and SPSS program (Statistical Package for Social Science) version 16 on Windows seven. The analysis of data done to test statistical significant difference between two groups for quantitative data normally distributed (mean \pm SD). Paired and unpaired student t-test was used to compare between the two studied groups at each time interval. A probability value of $\mathrm{P}<0.05$ was regarded statistically significant in these results.

\section{RESULTS}

\section{Marginal Bone height}

There was decrease in the mean value of marginal bone height surrounding the abutments throughout the study period in both groups. This decrease was highly significant in both groups throughout all intervals of follow-up period as shown in table (1).

There was statistically significant difference between the two studied groups in the decrease of marginal bone height through all intervals of follow-up period where group I showed less marginal bone resorption than group II as shown in table (2).

TABLE (1) Effect of time on marginal bone height in both studied groups at different intervals of follow-up period.

\begin{tabular}{|c|c|c|c|c|}
\hline & \multicolumn{2}{|c|}{$\begin{array}{c}\text { Group I: } \\
\text { Unsplinted }\end{array}$} & \multicolumn{2}{c|}{$\begin{array}{c}\text { Group II: } \\
\text { Splinted bar }\end{array}$} \\
\hline Period & $\begin{array}{c}\text { Mean } \\
(\mathrm{mm})\end{array}$ & SD & $\begin{array}{c}\text { Mean } \\
(\mathrm{mm})\end{array}$ & SD \\
\hline At-insertion & 12.475 & 0.142 & 12.437 & 0.113 \\
\hline At- 6 months & 12.156 & 0.076 & 12.123 & 0.123 \\
\hline At 12 months & 11.385 & 0.156 & 11.246 & 0.236 \\
\hline 0-6 months & \multicolumn{2}{|c|}{$0.0000672 * *$} & \multicolumn{2}{|c|}{$0.0000101 * *$} \\
\hline 6-12months & \multicolumn{2}{|c|}{$0.0001607 * *$} & \multicolumn{2}{|c|}{$0.0001328^{* *}$} \\
\hline 0-12 months & \multicolumn{2}{|c|}{$0.0000301 * *$} & \multicolumn{2}{|c|}{$0.0000476^{* *}$} \\
\hline
\end{tabular}

*P value < 0.05: significant. ** P value < 0.01: highly significant. $n s=P$ value $>0.05$ : non-significant

TABLE (2) Comparison between marginal bone 
height changes in both studied groups at different intervals of follow-up period.

\begin{tabular}{|c|c|c|c|c|c|}
\hline & \multicolumn{2}{|c|}{$\begin{array}{c}\text { Group I: } \\
\text { Unsplinted }\end{array}$} & \multicolumn{2}{c|}{$\begin{array}{c}\text { Group II: } \\
\text { Splinted bar }\end{array}$} & \\
\hline Period & $\begin{array}{c}\text { Mean } \\
\text { difference } \\
(\mathrm{mm})\end{array}$ & SD & $\begin{array}{c}\text { Mean } \\
\text { difference } \\
(\mathrm{mm})\end{array}$ & SD & P-value \\
\hline 0-6 months & 0.328 & 0.192 & 0.413 & 0.254 & $0.012^{*}$ \\
\hline 6-12 months & 0.654 & 0.378 & 0.691 & 0.440 & $0.043^{*}$ \\
\hline 0-12 months & 0.980 & 0.546 & 1.108 & 0.631 & $0.015^{*}$ \\
\hline
\end{tabular}

*P value < 0.05: significant. ** P value < 0.01: highly significant. $n s=P$ value $>0.05:$ non-significant

\section{Bone density}

There was increase in mean value of bone density throughout the study period in both groups. This increase was highly significant in both groups through all intervals of follow-up period as shown in table (3).

TABLE (3) Effect of time on bone density in both studied groups at different intervals of follow-up period.

\begin{tabular}{|c|c|c|c|c|}
\hline & \multicolumn{2}{|c|}{$\begin{array}{c}\text { Group I: } \\
\text { Unsplinted }\end{array}$} & \multicolumn{2}{c|}{$\begin{array}{c}\text { Group II: } \\
\text { Splinted bar }\end{array}$} \\
\hline Period & Mean (mm) & SD & Mean (mm) & SD \\
\hline At-insertion & 1007 & 35.257 & 1027 & 24.265 \\
\hline $\begin{array}{c}\text { At- 6 } \\
\text { months }\end{array}$ & 1074 & 37.846 & 1072 & 27.472 \\
\hline $\begin{array}{c}\text { At 12 } \\
\text { months }\end{array}$ & 1127 & 39.076 & 1124 & 19.510 \\
\hline P-value & \multicolumn{2}{|c|}{ P-value } \\
\hline 0-6 months & $0.0002052 * *$ & \multicolumn{2}{|c|}{$0.0013527 * *$} \\
\hline 6-12months & \multicolumn{2}{|c|}{$0.0007020^{* *}$} & \multicolumn{2}{|c|}{$0.0001146 * *$} \\
\hline 0-12 months & \multicolumn{2}{|c|}{$0.0002190^{* *}$} & \multicolumn{2}{|c|}{$0.0007979 * *$} \\
\hline
\end{tabular}

*P value < 0.05: significant. **P value < 0.01: highly significant. $N \mathrm{~s}=P$ value $>0.05$ : non-significant
There was statistically significant difference between the two studied groups on bone density during (0-12 months) interval, while there was no statistically significant difference through (0-6 months and 6-12 months) of follow-up period. Group I showed more increase in bone density than group II as shown in table (4).

TABLE (4) Comparison between changes in bone density in both studied groups at different intervals of follow-up period.

\begin{tabular}{|c|c|c|c|c|c|}
\hline & \multicolumn{2}{|c|}{$\begin{array}{c}\text { Group I: } \\
\text { Unsplinted }\end{array}$} & \multicolumn{2}{c|}{$\begin{array}{c}\text { Group II: } \\
\text { Splinted bar }\end{array}$} & \\
\hline Period & $\begin{array}{c}\text { Mean } \\
\text { difference } \\
(\mathrm{mm})\end{array}$ & SD & $\begin{array}{c}\text { Mean } \\
\text { difference } \\
(\mathrm{mm})\end{array}$ & SD & P-value \\
\hline $\begin{array}{c}0-6 \\
\text { months }\end{array}$ & 59 & 45.981 & 46 & 34.463 & 0.2636 \\
\hline $\begin{array}{c}6-12 \\
\text { months }\end{array}$ & 73 & 52.307 & 50 & 34.672 & 0.0655 \\
\hline $\begin{array}{c}0-12 \\
\text { months }\end{array}$ & 131 & 75.843 & 96 & 54.443 & $0.0428^{*}$ \\
\hline
\end{tabular}

$* P$ value $<0.05:$ significant. **P value $<0.01:$ highly significant. $N s=P$ value $>0.05$ : non-significant

\section{DISCUSSION}

The use of implants in the distal extension areas within different removable partial dentures has been recommended. ${ }^{(20)}$ Such implant will increase the stability of the removable denture, preserve supporting bone, and enhance retention..$^{(20)}$

Single implant and single tooth abutment supported overdenture is an alternative method for removable partial denture, especially in mandibular arch which usually suffers from inadequate surface area is considered a brave for the prosthodontists ${ }^{(20)}$.

Many different modality for implant-supported overdenture attachments, with no difference in implant survival rates, peri-implant outcome and patient satisfaction regardless of splinting. ${ }^{(22)}$ However, several articles showed that the nonsplinted design requires more prosthetic maintenance and the bar attachment system has been 
shown to be a more successful prosthesis. ${ }^{(22)}$ While bar system has the best maintainability. ${ }^{(23)}$ For this reason, the bar attachments were selected in this study, to retain the single implant and natural teeth abutment (mandibular canine).

A parallel long cone extension technique was used to avoid any elongation or shortening of the images. All radiographs were taken with the same voltage, intensity, film type and speed to allow standardization. Moreover, this technique eliminates the possibility of superimposition over other structures ${ }^{(24)}$.

Radiographic template was fabricated for each patient to duplicate the target of imaging ${ }^{(25,26)}$. To exclude any differences in film density either during imaging or processing a stepwedge tool was used.

Digora was one of the most distributed software in the literatures either using direct or indirect techniques for digital radiography. It was an efficient and simple method to evaluate bone height and bone density it provides fast, easy and more accurate results ${ }^{(19-22)}$. The maximum follow-up time for evaluation was twelve months because at which the maximum changes occurred ${ }^{(27)}$.

From the results of this study, the bone density appeared to be increased gradually which could be claimed to the positive response to the applied force, as the natural tooth can adapt to normal or avoid heavy occlusal load through the thickness and closeness of bone trabeculae vary directly with the stress transmitted to them. The findings of marginal bone height change of the non connected abutments group are in agreement with other study used implant and natural tooth as overdenture abutments over a one year period ${ }^{(28,29)}$. who's showed increase in marginal bone density in response to function. The results also are in accordance with several studies used natural abutments in conventional overdenture $^{(13,30,31)}$.

The bar connected abutments group showed reduction in bone density after three months period. This result could be explained on the basis of increased unfavorable loading during function. The use of rigid fixation between the overdenture and the implant induce horizontal forces on the implant and thereby increases bone resorption around implant ${ }^{(32,33)}$. The lateral stresses are destructive in nature and may exceed the physiologic limit that the tooth can withstand. These results agreed with Higazy ${ }^{(23)}$ who pointed out the effect of connection upon the amount of load transferred to abutments and was recommended separation between implant and tooth.

The results also demonstrated significant reduction in bone height if the two abutments (natural tooth and implant) were rigidly connected with bar in comparison to the non connected abutments group. That could be claimed to the difference in the supporting nature between the natural tooth and the implant. The response of the peri-implant tissues to load application is completely different than the periodontal ligaments ${ }^{(34)}$.

The implant moved as a result of bone flexure leading to narrow range of movement while the periodontal ligaments are stretched then the bone elastically deformed giving the tooth a wide range of movement ${ }^{(34)}$. That could be one reason for a greater bone loss seen around the splinted abutments. More movements allowed in between abutments and overdentures as in non connected abutments group might facilitate greater freedom of the denture which consequently can create favorable loading condition for both supporting structures.

On the other hand, the results of this study are in disagreement with the proponents of the rigid connection between teeth and implants ${ }^{(27,35,36)}$.

The present investigation reported more significant increase in bone density between non connected abutments group than the bar connected abutment group. The non connected abutments group may have better stress distribution over abutments and better dissipation of the undesirable lateral stresses that may endanger the periodontium of the tooth. 


\section{REFERENCES}

1. Jacobson TE, Krol AJ. A contemporary review of the factors involved in complete denture retention, stability, and support. Part I: retention. J Prosthet Dent 1983;49:5-15.

2. Donatsky O. Osseointegrated dental implants with ball attachments supporting overdentures in patients with mandibular alveolar ridge atrophy. Int J Oral Maxillofac Implants 1993;8:162-166.

3. Hickey, J.C., Zarb, G.A., Bolender, C.L.: Bouchers' prosthodontic treatment for edentulous patients. $9^{\text {th }}$ ed. C.V. Mosby Co., St.louis, London ,(1985) pp.(243-265).

4. Holmgren EP, Seekinger RJ, Kilgren LM, Mante F. Evaluating parameters of Osseointegration dental implant using Finite-element Analysis. J Oral Implant 1998;24:80-8.

5. Akca K. Iplikcioglu H. Finite-element stress analysis of the effect of short implant usage in place of cantilever extensions in mandibular posterior edentulism. J Oral Rehabil 2002;29:350-6.

6. Kurian BP, D'lima J, Karthikeyan CR, Mathew J, Paul T, Hareesh MT. Prosthetic efficiency of implant-supported overdentures with locator attachment: A clinical case report. J Int Oral Health 2015;7:129.

7. Chung KH, Chung CY, Cagna DR, Cronin RJ Jr. Retention characteristics of attachment systems for implant overdentures. J Prosthodont 2004;13:221-6.

8. Liddelow GJ, Henry PJ. A prospective study of immediately loaded single implant-retained mandibular overdentures: Preliminary one-year results. J Prosthet Dent 2007;97 6 Suppl: S126-37.

9. Walton JN, Glick N, Macentee MI. A randomized clinical trial comparing patient satisfaction and prosthetic outcomes with mandibular overdentures retained by one or two implants. Int J Prosthodont 2009;22:331-9.

10. Klemetti E. Is there a certain number of implants needed to retain an overdenture? J Oral Rehabil 2008;35 Suppl $1: 80-4$.

11. Alsabeeha NH, Payne AG, De Silva RK, Thomson WM. Mandibular single-implant overdentures: Preliminary results of a randomised-control trial on early loading with different implant diameters and attachment systems. Clin Oral Implants Res 2011;22:330-7.

12. Alsabeeha NH, Swain MV, Payne AG. Clinical performance and material properties of single-implant overdenture attachment systems. Int J Prosthodont 2011; 24:247-54.
13. Omran AO, Fouad MF, Elsyad MA. Effect of different attachments designs used for implant assisted mandibular distal extension RPD. An in vitro study of stresses transmitted to abutment teeth. Mansoura J Dent 2014;1:124-30.

14. Carpentieri, J.: Treatment options for the edentulous mandible: clinical application of the two-implant overdenture. Pract Proced Aesthet Dent 16(2):105-112; 2004.

15. Cohen, S.R., and Orenstein, J.H.: The use of attachments in combination implant and natural-tooth fixed partial dentures: a technical report. Int J Oral Maxillofac Implants 9(2):230-234; 1994.

16. El-Charkawi, H.G., Zekry, K.A., and El-Wakad, M.T.: Stress analysis of two osseointegrated implants supporting distal extension prosthesis. Al-Azhar Dent J; 7:347-362; 1992.

17. El-Charkawi, H.G.: Connecting implants to natural teeth. Problems and solutions. Implants and future, $1^{\text {st }}$ International Implantology Conference, March: 91, 1995.

18. Becker, C.M., Kaiser, D.A., and Jones, J.D.: Guidelines for splinting implants. J Prosthet Dent; 84:210-4; 2000.

19. El-Gaaly K: Smoking in dental practice. Journal of ESSDI 2007; 4: 54-61.

20. Vahidi F, Pinto-Sinai G. Complications associated with implant-retained removable prostheses. Dent Clin North Am 2015;59:215-26.

21. Heartwell, C.M.; and Rahn, A.O.: Syllabus of complete denture, 4th ed. Lea \& Febiger, Philadelphia, (1986); pp. (499-505).

22. Kopp, C.D.: Overdentures and osseointegration. Case studies and treatment planning. J. Dent. Clin. North. Am., 34:729-739; 1990.

23. Weinberge, L.A.: Tooth and Implant-supported prosthodontics. Quintessence Books Inc. (1998); pp (47-67).

24. Plotnick, I.J., Beresin, V.E., and Simkins, A.B.: A technique for standardized serial dental radiographs. J Periodontol 6:297-301; 1971.

25. El-hadary, A.A.: Immediate loading versus delayed loading of implant supported mandibular overdenture. $\mathrm{PhD}$ Thesis, Faculty of Dentistry, Ain-shams University, 2003.

26. Azzam, M.E.: Telescopic crown versus extracoronal attachment as retiners for removable partial dentures. Ph.D Thesis, Faculty of Dentistry, Ain shams University, 2004. 
27. Davarpanah, M., and Martinez, H.: Clinical manual of implant dentistry. Quintessence Publishing Co, Ltd. 2003. pp. (67-89).

28. Higazy, A.K.: Splint bar versus individual copings in tooth implant restoration (A two years longitudinal study). Ph.D Faculty of Oral and Dental Medicine. Cairo University, 1999.

29. Baker, J. and Goodkind, R.J.: Immediate placement and implant loading for expedited patient care; A patient report. Int J Oral Maxillofac Implants 17: 587; 2002.

30. Bolouroi, A.: Proposed treatment sequence for overdentures. J Prosthet Dent 44, 3: 247-250; 1980.

31. Ettinger, R.L., Taylor, T.D., and Scandrett, F.R.: Treatment needs of overdenture patients in a longitudinal study: fiveyear results. J Prosthet Dent 52, 4: 532-536; 1984.

32. Krennmair, G., and Ulm, C.: The Symphyseal Single-tooth Implant for Anchorage of a Mandibular Complete Denture in Geriatric Patients: A Clinical Report. Int J Oral Maxillfac Implants 16:98-104; 2001.

33. Cordioli, G., Majzoub, Z., and Castagna, S.: Mandibular overdentures anchored to single implants: a five-year prospective study. J Prosthet Dent 78(2):159-65; 1997.

34. Mericske-Stern, R.: Overdentures with roots or implants for elderly patients: a comparison. J Prosthet Dent, 72(5): 543- 550; 1994.

35. Ibrahim, A.M.: Evaluation of single implant Assisting single natural abutment under complete mandibular overdenture. Ph.D Thesis. Faculty of Oral and Dental Medicine. Cairo University, 1997.

36. Menicucci, G., Mossolov, A., Mozzati, M., Lorenzetti, M., and Preti, G.: Tooth-implant connection: some biomechanical aspects based on finite element analyses. Clin Oral Implants Res; 13:334-41; 2002 